\title{
A TRAJETÓRIA INTELECTUAL DE ROQUE SPENCER MACIEL DE BARROS ${ }^{1}$
}

Paulino José Orso ${ }^{2}$

\section{RESUMO}

Neste artigo, apresentamos a trajetória de Roque Spencer Maciel de Barros, um intelectual convictamente liberal, que dedicou praticamente toda sua vida, quer seja como docente da USP ou como editorialista do Jornal $O$ Estadão, à defesa incondicional do liberalismo, entendendo-o como expressão da "boa sociedade". Com a mesma intensidade com que defendia o liberalismo, também combatia aquilo que denominava de totalitarismo. Enquanto docente, participou ativamente da Campanha em defesa da escola pública, ajudou a criar a faculdade de educação e não deixou apenas sua marca como professor e Chefe de Departamento da Universidade de São Paulo. Também ocupou diversos cargos e participou da Reestruturação desta instituição. Além disso, foi nomeado pessoalmente pelo Presidente Costa e Silva para integrar o grupo da Reforma Universitária, no qual atuou procurando "recolocar a universidade nos trilhos", em sintonia com os ideais liberais preconizados pelos seus idealizadores. Em síntese, apresentamos um autor que defende a teoria liberal, posiciona-se em defesa da escola pública no final dos anos 1950 e início dos anos 1960, mas alia-se ao governo militar na Reforma Universitária e na reestruturação da USP, bem presta apoio à ditadura de Pinochet.

Palavras-chaves: Educação; liberalismo; reforma universitária.

\section{THE INTELLECTUAL TRAJECTORY OF ROQUE SPENCER MACIEL DE BARROS}

\begin{abstract}
In this article, we present the intellectual trajectory of Roque Spencer Maciel de Barros, an intellectual conviction liberal, who devoted most of his life, either as a teacher or as the USP of the Journal editorialist Estadão, the unconditional defense of liberalism, understood as expression of the "good society". With the same intensity with which he defended liberalism also fought what he called totalitarianism. While teaching, actively participated in the campaign in defense of public schools, helped create the college of education and not just left its mark as Professor and Head of Department at the University of São Paulo. He also held several positions and participated in the restructuring of this institution. In addition, he was appointed personally by President Costa e Silva to join a group of University Reform, which served looking "Replacing the university on track" in line with liberal ideals advocated by its founders. In summary, we present an author who advocates the liberal theory, ranks in defense of public schools in the late 1950s and early 1960s, but it is allied to the military government in university reform and restructuring of the USP and provides support the Pinochet dictatorship.
\end{abstract}

Keywords: Education; liberalism; university reform. 


\section{Trajetória de vida}

Entendemos que é importante apresentar a trajetória intelectual de Roque Spencer Maciel de Barros, tanto para facilitar a compreensão do autor, como para entender sua concepção de liberalismo e a influência que exerceu na educação. Primeiro trataremos de sua trajetória mais diretamente relacionada ao liberalismo e depois, de sua formação e seu percurso na educação.

Roque Spencer Maciel de Barros, filho de Paulo Maciel de Barros e Leontina Albuquerque Maciel de Barros, nasceu em Bariri, no interior de São Paulo, no dia 05 de abril de 1927. Passou sua infância e adolescência em São Joaquim da Barra; iniciou seus estudos no interior do Estado e os completou na capital, onde viria a viver e desenvolver sua atividade profissional.

Casou-se duas vezes. A primeira, com Maria da Conceição Rabêllo de Barros, com quem teve três filhos (Angela Rabello Maciel de Barros, Saulo Rabello Maciel de Barros e Rubem Rabello Maciel de Barros) e a segunda, com Gilda Naécia Maciel de Barros, com quem conviveu até o final de sua vida.

Dentre os teóricos do liberalismo e da educação brasileira Roque Spencer destaca-se tanto por suas pesquisas e seus escritos, como pela defesa intransigente que fez do liberalismo, pelo combate ao totalitarismo e pela "defesa da Escola Pública" na segunda metade da década de 50. Sua obra é bastante extensa, porém, circunscreve-se basicamente em torno do liberalismo. Mesmo quando trata do totalitarismo e da educação, o faz sob a perspectiva do liberalismo.

$\mathrm{O}$ autor dedicou sua vida profissional à educação formal, mas fez desta, digamos assim, uma espécie de laboratório para as pesquisas e defesa de sua cosmovisão liberal. Com a mesma finalidade, sistematicamente, escrevia artigos e os publicava nos jornais $O E S P$ e Jornal da Tarde ${ }^{3}$, através dos quais, pretendia atingir e educar a sociedade. Afirmava que, aos cinco anos, sua mãe o alfabetizou com as páginas do $O$ Estado de $S$. Paulo e que em sua casa nunca entrou outro jornal a não ser este. No dia 15 de março de 1948, quando ainda era aluno, começou a trabalhar para o referido jornal como redator na seção de política internacional. Depois, além de articulista, foi editorialista para assuntos educacionais. Afirmava que os diretores do $O E S P$ foram seus colegas de turma na Faculdade de Filosofia e estava profundamente ligado a eles "por relações de amizade e coincidência de pensamento, desde vinte anos". Quanto ao Jornal da Tarde, começou "a colaborar desde o seu primeiro ano" (BARROS, 1971, p. 11. Parêntese nosso). Os artigos de Roque Spencer versavam principalmente sobre Filosofia, Filosofia da Educação e Filosofia Política (liberalismo). Além disso, escreveu ensaios, organizou e publicou diversos livros.

Em 1946, quando ingressou no Curso de Filosofia da Faculdade de Filosofia, Ciências e Letras da USP, já defendia os princípios do liberalismo. Definindo-se como liberal, começou a escrever artigos relacionados ao liberalismo, propondo soluções para o país a partir desta perspectiva. Tal atividade iria ampliar-se nos anos 1950 e 1960 e resultar no livro denominado Introdução à filosofia liberal (1971). Mais tarde, reunindo uma série de artigos sobre a mesma temática, organizou e publicou Estudos liberais (1992) e Razão $e$ Racionalidade (1993), obras em que revela o seu compromisso com a defesa das soluções liberais, tidas por ele como as mais eficazes e as melhores possíveis para a organização e sobrevivência de uma "boa sociedade". 
Roque Spencer tornou-se uma espécie de "militante" do liberalismo; defendeu esse ideário, seus princípios e seus fundamentos com todas as suas forças. Dedicou-se à tarefa de desfazer confusões, esclarecer e precisar determinados termos que considerava fundamentais para evitar mal entendidos acerca do liberalismo e prevenir que os menos incautos, pensando defender o liberalismo, acabem por comprometê-lo.

Para ele, a sobrevivência do liberalismo depende fundamentalmente da derrota do totalitarismo. Por isso o combate como uma espécie de obsessão. Nesse sentido, grosso modo, pode-se dizer que a defesa do liberalismo resume-se ao ataque ao comunismo: "Ah! Anticomunista, sou, sem dúvida" (cf. BUFFA e NOSELLA, 1986, p. 50), afirma o autor. Apesar de dizer, que mais do que o triunfo do liberalismo importa-lhe a afirmação de um "modelo" coerente, na prática não só defende que é preciso combater os "intolerantes", ou seja, aqueles que não comungavam com o liberalismo, como apoia à ditadura em nome da defesa da "liberdade".

A despeito de ser vasta e aparentemente diversa, a sua obra unifica-se em torno da defesa do ideário liberal, na aversão a qualquer forma de absoluto (menos o liberalismo); circunscreve-se em torno da antinomia liberdade X totalidade. É importante dizer que o autor faz uma distinção entre racionalidade ${ }^{4}$ e Razão ${ }^{5}$. Vincula aquela à atividade de análise, de crítica e de conhecimento, concebidos como relativos e esta ao totalitarismo.

A partir da ótica liberal Roque Spencer também estudou o positivismo, que denomina de cientificismo ou de cientismo ${ }^{6}$ e o romantismo. Nos anos cinquentas e posteriores, no momento em que os intelectuais e políticos estavam preocupados em discutir a dependência e as possíveis alternativas para superar o atraso e promover o desenvolvimento do país, o autor voltou-se para o passado e estudou como os liberais, os românticos e os cientificistas concebiam a realidade brasileira e quais as saídas que defendiam para superar o subdesenvolvimento a que o país estava submetido.

Dentre os positivistas, estudou principalmente a vida e a obra de Luiz Pereira Barreto (sua tese de doutorado), a quem considera “o primeiro positivista brasileiro 'completo' e percuciente analista da problemática nacional (BARROS, 1967, Vol. 1, p. 9) ${ }^{7}$. Quanto ao Romantismo, que é representado no Brasil principalmente por Gonçalves de Magalhães, o autor diz que foi a primeira filosofia a inspirar a busca de nosso destino como nação. Mesmo sendo uma inspiração europeia, diz Roque Spencer, ela nos aponta uma tarefa antes de tudo nacional; convida-nos a descobrir o nosso próprio ser, isto é, a buscar o universal, a "totalidade" através do particular.

De acordo com esta perspectiva, diz que o romantismo se afirmou com a independência e vigorou até aproximadamente 1870. Daí em diante instalou-se no país uma forma diversa de conceber a história nacional e de interpretar o mundo e o homem, própria do cientificismo naturalista, fundada numa visão universalizante e na lei do acontecer histórico único, baseada numa filosofia progressista da história e no princípio de que as diferenças entre os povos não são de natureza e, sim, de fase.

Ao longo de sua obra, Roque Spencer chama a atenção repetidas vezes sobre os problemas do cientificismo, da ideologia e, sobretudo, do totalitarismo que, para ele, constituem-se em "ameaças à liberdade"; considera que sempre é pouco o que se diz e rediz sobre estas questões, tendo em vista os perigos que representam (1971, p. 14).

$\mathrm{O}$ autor dedicou praticamente toda sua vida à atividade educativa. Foi um estudioso incansável; pesquisou a história da cultura desde a antiguidade até nossos dias, 
principalmente a filosofia, a educação, as questões ligadas ao liberalismo, ao totalitarismo, à ética, à religião, à mitologia, ao romantismo e ao positivismo. Porém, sua preocupação pedagógica ultrapassava a universidade. Através dos jornais e dos livros propõe-se a educar toda a sociedade.

Segundo Roque Spencer, a publicação de artigos em jornal revestia-se de muita importância. Principalmente quando entendida de acordo com o pensamento do antigo redator de O ESP e da Folha da Noite, da Folha da Tarde e da Folha da Manhã, Olival Costa, para quem a função do jornal não é apenas informar e noticiar: é, a um só tempo, selecionar e orientar (cf. MOTA \& CAPELATO, 1981, 15). Ou, como entendia Plínio Barreto, que também foi diretor de $O E S P$ :

'um verdadeiro jornal é a publicação onde por meio de notícias e de artigos se dão alimento à curiosidade do público e normas para a disciplina do seus espírito e de seus costumes ... constitui para o público uma verdadeira bênção. Dispensa-o do trabalho de formar ideias. Dá-lhes já feitas e polidas todas as tardes, sem disfarces e sem enfeites, lisas, claras e puras' (CAPELATO \& PRADO, 1980, p. 95).

Nesse sentido, Roque Spencer desenvolve um intenso trabalho como articulista e editorialista procurando atingir e educar toda a sociedade com base nos princípios liberais. Mas, diz ele: "sabemos todos qual o destino de artigos de jornais. Lidos, esquecidos às vezes, muitas das ideias ventiladas acabam dando frutos aqui e ali, sem que se possa dizer com precisão até que ponto o artigo influiu" (1967, Vol. I, p. 253). Assim, insatisfeito com o destino incerto de seus artigos, depois de publicá-los nos jornais, reúne-os e os publica na forma de livros, como se quisesse dar uma sobrevida a eles.

Quanto à postura filosófica, ao discorrer sobre a conduta animal e a conduta humana, diz que, no final dos anos de 1970, com o aprofundamento de suas investigações sobre o fenômeno totalitário, suas convicções evoluíram do idealismo para o "empirismo transcendental" (BARROS, 1993, p. 263). Contudo, apesar de ter incorporado em sua cosmovisão a base biológica da conduta humana, que dizia estar escamoteada e mascarada pelo idealismo, não consegue romper com o idealismo.

Apesar das aproximações, Roque Spencer não concorda que o classifiquem como culturalista, como o faz Antônio Joaquim Severino ${ }^{8}$. Antonio Paim diz que, apesar de estar muito próximo do culturalismo, não pode ser classificado como pertencente a esta corrente (1984, p. 528). Ele se auto-define como simplesmente um liberal. Dizia: "não gosto dos istas e dos ismos. Só sei que, politicamente, sou um liberal, que detesta o rótulo de neoliberal"9.

Aposentou-se cedo, aos 56 anos de idade. Entretanto não abandonou suas atividades intelectuais. Ao contrário, a partir daí, tornou-se ainda mais intensa do ponto de vista de suas preocupações. Continuou a escrever artigos e livros, fiel ao espírito liberal.

\subsection{A construção da imago mundi e da imago hominis}

É no final do curso clássico e no início do curso superior que Roque Spencer praticamente constrói e define sua imago mundi e sua imago hominis, a concepção de mundo e de homem que o acompanhariam por toda vida. 
Relata que, em 1945, no final da Segunda Guerra Mundial estava com 18 anos de idade quando fazia o último ano do curso clássico e que, além de Matemática, Física, Química, Biologia, História, Geografia, Grego, Latim, estudava Filosofia. Seu professor era Laerte Ramos de Carvalho, que já o havia sido no segundo ano do clássico no Colégio Paulistano e de quem viria a tornar-se assistente na antiga FFCL da USP, além de grande amigo $^{10}$. Diz que, como tinha que fazer um trabalho no final do curso, influenciado pelos horrores da guerra e pelo existencialismo, então em voga, decidiu fazê-lo sobre a angústia tendo como principal referência o pensamento de Heráclito, o filósofo pré-socrático que o marcou por toda a vida. Nas recordações de Heráclito, afirma ele:

é a minha recordação do filósofo de Éfeso, estreitamente ligada ao fim de minha adolescência, à minha formação e à definição de minha imago mundi, que envolve também - e naturalmente - uma imago hominis (BARROS, 1993, p. 209).

Nesse momento, além do pensamento de Heráclito, travou contato com Nietzsche $(A$ origem da tragédia), Kierkegaard ( $O$ conceito de angústia), Gurvitche (As tendências atuais da filosofia alemã), Alberto W. Reyna (A ontologia fundamental de Heidegger) e Rivaud (As grandes correntes do pensamento antigo), dentre outros que viriam a influenciá-lo.

O Heráclito de Roque Spencer, o "meu Heráclito", como se refere, é marcado pelas limitações culturais do momento. Ainda eram poucos os fragmentos heraclitianos de que se tinha conhecimento no Brasil e poucas eram as obras escritas sobre ele que haviam chegado até aqui. Nem fazia ideia dos debates sobre as relações entre Heráclito e Parmênides travados a partir da obra de Karl Reinhardt, Parmênides e a Filosofia grega (Idem. p. 213). Contudo, afirma que elas têm pouco a ver com as suas "recordações de Heráclito" que, deslocando o problema da metafísica-cosmológica para a physis, descobre-se diante da questão do "eterno vir-a-ser", da transformação permanente. É com este Heráclito que Roque Spencer se identifica, "um Heráclito que talvez seja eu mesmo", diz ele, à procura dos seus caminhos de existência em relação aos métodos de pensar e trabalhar, mas principalmente, em face do próprio mistério do existir; um Heráclito que se opõe à fixidez e que se afirma na "angústia humana diante do fluir das coisas que, inexoravelmente, nos conduz para alguma parte que não sabemos qual seja, sem que nos seja concedido, sequer, a possibilidade de banhar-nos duas vezes no mesmo rio" (Idem. p. 211).

Depois de travar conhecimento sobre as polêmicas em torno de Heráclito e Parmênides, com E. Zeller diz que

'enquanto Parmênides nega o devir para manter o conceito do ser em toda a sua pureza, Heráclito, ao contrário, nega o ser para conservar em toda a sua integridade a lei do devir. Enquanto o primeiro vê a ideia de mudança e de movimento como uma ilusão dos sentidos, o segundo descobre tal ilusão na ideia do ser persistente. Enquanto um considera absurda a opinião comum, porque ela admite o nascimento e a morte, o outro chega à mesma conclusão quanto ao seu absurdo, partindo da opinião contrária' (Idem. p. 217). 
Parmênides e Heráclito apresentam duas formas diferentes de compreender e resolver o problema do "posto do homem no cosmos"11. Porém, é com o filósofo obscuro, como Diógenes de Laércio denominava Heráclito, que Roque Spencer se identifica.

Sua experiência fundamental da temporalidade e da angústia perante o devir, que o autor denominou de entre sentimental e mental, teve início ainda na adolescência. Depois de concluir o curso colegial e prestar o exame do vestibular para o curso de Filosofia, tendo ainda bem presentes suas reflexões heracliteanas, foi para um sítio em Caieira, no interior de São Paulo, enquanto esperava o resultado da seleção. Relata que ao vaguear sozinho por uma trilha em meio a um grande arvoredo, teve a "intuição original" que marcaria definitivamente a sua maneira de compreender o homem. Em suas Recordações de Heráclito, dizia que,

de repente no esplendor da tarde de verão, eu me senti uma parte ínfima de uma imensa natureza que me tragava e com a qual eu respirava e vivia, compartilhando a imanência de todas as coisas na unidade de uma coisa única. Mas ao mesmo tempo, de forma ambígua, eu, ser consciente que tinha diante de mim o espetáculo de um mundo que me parecia virgem e como que visto pela primeira vez, sentia-me emergir dessa unidade e separar-me dela de forma irreparável: imanente a ela, eu a transcendia; entre mim e ela era necessária uma mediação, mediação que se esboçava já no meu sentimento do mundo e que se clarificava no ato de pensar a própria situação que eu experimentava (...). Era o meu íntegro, corpo e pensamento, que, imanente ao mundo, ao mesmo tempo o transcendia - e, nessa transcendência, que me revelava o meu estar no mundo sem me confundir com ele, sem ser o mundo, eu sentia o imenso abismo da liberdade, como algo que brotava do simples fato de ser eu diante do cosmos e de saber que o era $(1993$, pp. 211, 212).

Em poucas palavras este relato expressa aquilo que orientaria para sempre sua compreensão de homem no mundo. Mais tarde, a 07 de março de 1946, através de um poema que denominou de Ensaio de interpretação da liberdade expressou sua "intuição original" nos seguintes termos:

Emerges lentamente do universo para, transcendendo, te fazeres homem.

Trazes nos olhos uma tragédia mal desvendada que te separa do mundo ventre, opaco e neutro.

Emparedado na tua liberdade, estás irremediavelmente só no centro do universo.

E carregarás tua solidão e teu abismo, lúcido e livre, até a queda no todo indiferente.

Só e livre, à espera do gozo da dissolução na morte (Idem. p. 212).

Inspirado na leitura dos fragmentos de Heráclito, Roque Spencer constrói sua imagem de homem e de mundo debatendo-se entre os limites da natureza e da afirmação da 
liberdade ou, se se quiser, entre a tragédia e a liberdade. Através da poesia, que aprendeu a gostar com Geraldo Rodrigues, seu professor de português do ginásio em Orlândia (Cf. BARROS, O Estado de S. Paulo. 03/04/84), expressa sua tarefa insubstituível; manifesta sua paixão pela liberdade e sua aversão pela totalidade; declara sua compreensão de vida e de mundo; revela a insustentável leveza, a miséria e a grandeza do ser.

Benedicto Ferri de Barros diz que na década de 1940, quando ainda era possível varar a noite e entrar pela madrugada trocando ideias peripateticamente pelas ruas de São Paulo, partilhou por anos a fio ideias, ideais, amizade pessoal, intelectual, filosófica e literária com Roque Spencer, e já se surpreendia com sua memória prodigiosa, sua prematura erudição, a seriedade e a profundidade com que se aplicava aos estudos de filosofia. Mais tarde, por mais de um decênio, fez parte de um grupo de professores da USP e outros intelectuais que, por rodízio, reuniam-se na casa de um ou de outro para cultivar as produções literárias, a poesia, a prosa, e para conversar informalmente.

Por ocasião do falecimento de Roque Spencer, Ferri de Barros se referiu da seguinte forma em relação a seu amigo. Diz ele: em 1964, quando

buscávamos esperançosos e angustiados rumos novos para o País, foi a Roque que recorri, a fim de que organizasse para essas reuniões um plano de leituras e estudos que nos atualizasse quanto a caminhos alternativos às extremidades políticas que engolfavam nossa terra. Vieram daí, naquele regime de rodízio, dezenas de reuniões em que, por indicação de Roque e sob sua segura direção intelectual, tomamos conhecimento das grandes obras do liberalismo desencadeadas a partir do Colóquio Walter Lippmann, realizado em 1938. Vieram daí também as colunas em que, por dezenas de anos, Roque, eu e Geraldo Pinto Rodrigues nos dedicamos n'O Estado de S. Paulo e no Jornal da Tarde a difundir essas ideias, ainda em pleno período da ditadura militar, e que a generosidade da vida nos permitiu ver vencedoras na atualidade do mundo e do Brasil (FERRI DE BARROS. 10/05/1999).

Segundo Ferri de Barros foi nessa trilha que Roque Spencer prosseguiu seus estudos por décadas e de onde surgiu, por exemplo, O fenômeno totalitário, que é a obra de maior amplitude escrita no Brasil sobre o totalitarismo.

\section{2 - A formação e a trajetória na educação}

Como já mencionamos, ao longo de toda a vida e a obra de Roque Spencer, encontramos sua preocupação com a defesa do liberalismo e, consequentemente, com o combate a todas as outras possíveis filosofias e/ou formas de organização social, tidas por ele como se fossem totalitárias ou, pelo menos, como portadoras de indícios totalitários, quer seja o positivismo, o estruturalismo, o marxismo, o socialismo ou as igrejas, as teologias, os nazismos, os fascismos ou qualquer outra forma que não seja orientada pelos princípios liberais. Para ele, todos têm um fundo totalitário. A defesa do liberalismo está acima de tudo; considera-o como a melhor filosofia, senão a única, que possibilita organizar a "boa sociedade". Simplificando pode-se dizer, que para o autor, a sociedade divide-se entre os que defendem a liberdade e os contrários a ela, os defensores do totalitarismo. Dito de outro 
modo, poder-se-ia afirmar que para o autor é o liberalismo ou a impossibilidade da vida social.

Entre 1939 e 1942 cursou o ginásio no Liceu Municipal de Orlândia e entre 1943 e 1945 cursou o colegial no Colégio Paulistano, em São Paulo, capital. A seguir entrou para a Universidade e, em 1948, graduou-se Bacharel em Filosofia pela Faculdade de Filosofia, Ciências e Letras da Universidade de São Paulo (FFCL/USP) e, um ano depois, em 1949, obteve o grau de licenciado na mesma disciplina.

Enquanto aluno trabalhou nos antigos colégios Carlos Gomes, Eduardo Prado, Colégio Paulistano, Franco-Brasileiro, Pasteur e Mackenzie, na capital paulista onde lecionava Filosofia. Posteriormente, em 1951, o Prof. João Cruz Costa o convidou para ser professor Extra-Numerário (colaborador) na FFCL/USP. Em novembro de 1951 foi contratado como Professor Assistente. Em 1955 concluiu o Curso de Doutorado ${ }^{12}$ em História e Filosofia da Educação e, em 1959, obteve o título de Livre-docente ${ }^{13}$ na mesma disciplina e na mesma instituição. Em 1968 passou a Professor Adjunto ${ }^{14}$ na FFCL e exerceu essa função até 1970. Depois, com a criação da Faculdade de Educação como unidade autônoma, que ajudou a fazê-lo, foi Professor Adjunto dessa Faculdade até 1973, quando obteve o título de Professor Titular ${ }^{15}$, também em História e Filosofia da Educação. Portanto, exerceu praticamente toda sua vida profissional como professor na USP.

Enquanto aluno do curso superior teve como professores: Fernando de Azevedo, João Cruz Costa, Eurípedes Simões de Paula, Antonio Cândido de Mello e Souza, Gilles Gaston Grangé, Martial Gueroult, Otto Klinberg e Laerte Ramos de Carvalho, dentre outros. Assistiu conferências de Roger Dion, Fernand Braudel, Georges Gurvitch e outros. Além de ter sido um estudante dedicado, culto e erudito ${ }^{16}$, Roque Spencer foi pesquisador, professor de História e Filosofia da Educação, escreveu artigos, ensaios e livros, ministrou cursos, proferiu conferências, orientou alunos de mestrado e doutorado, participou de bancas examinadoras, foi representante dos Livre-docentes junto à Congregação da FFCL/USP entre 1961 a 1965; foi Chefe do Departamento de Educação na FFCL/USP entre 1967 e 1969; foi membro e relator da Comissão de Reestruturação da Universidade de São Paulo entre 1966 e 1968; foi Chefe do Departamento de Filosofia da Educação e Ciências da Educação da Faculdade de Educação da USP de 1970 a 1976 e de 1980 a 1984. Entre 1976 e 1980 ocupou o cargo de Diretor da Faculdade de Educação da USP. Além disso, foi membro do Conselho Universitário, membro da Câmara de Graduação, membro do Conselho de Ensino, Pesquisa e Extensão de Serviços à Comunidade, membro da Comissão de Legislação e Recursos, membro da Comissão Editorial e Vice-Diretor do Conselho Administrativo da Fundação Universitária para o Vestibular (FUVEST). Depois de sua aposentadoria, continuou vinculado à Faculdade de Educação ministrando cursos sobre Liberalismo, Ética, Estado e educação, etc. Também foi membro efetivo do Instituto Brasileiro de Filosofia e do Instituto de Filosofia Luso-Brasileira.

Em se tratando de sua preocupação com a educação, acontece a mesma coisa que com o liberalismo. Sendo defensor de uma educação orientada pelos princípios liberais, atua no sentido de identificar, defender e propagar os autores, as ideias e as teorias que comungam com essa mesma concepção. Tendo compreendido cedo o sentido da mensagem de Júlio de Mesquita Filho e de Armando de Salles Oliveira, os principais idealizadores da USP, procurou fazer da educação tanto um meio de propagar os princípios liberais como de promover as "grandes transformações de que o Brasil estava necessitando. Em 1959 e início 
dos anos 60, trava uma intensa luta a favor da Escola Pública, Gratuita e Universal e combate duramente os que se opõem a ela. Seguindo os mesmos princípios liberais, em 1968 também exerceu forte influência na reestruturação da USP, da qual foi relator da Comissão de Reestruturação e na criação da Faculdade de Educação em 1970. Em 1968 também fez parte do GTRU, criado pessoalmente pelo General Costa e Silva.

Roque Spencer fez parte da Comissão Estadual em Defesa da Escola Pública (CEDEP), foi responsável pela elaboração do Roteiro para a Defesa da Escola Pública e preparou diversas Emendas ao projeto de Diretrizes e Bases da Educação Nacional (DBEN) que foram enviadas ao Senado da República. Enquanto integrante da CDEP participou de debates, escreveu artigos em jornais e revistas, organizou e publicou livros com a preocupação de defender o ensino público, combater as posições contrárias à defesa da Escola Pública e responsabilizar o Estado pela manutenção da mesma.

De acordo com José Mário Pires Azanha, em palestras, reuniões públicas e artigos pela imprensa, Roque Spencer foi "incansável” na defesa dos princípios liberais e da escola democrática, laica e gratuita. Segundo autor,

o que o situou de modo muito especial nessa campanha foi o fato de ter escolhido como tema principal de combate o princípio da liberdade de ensino, que o Deputado Carlos Lacerda alegava ser o leitmotiv filosófico de seu substitutivo. Naquele momento, os que tomavam posição contrária a esse projeto eram pronta e levianamente acusados de adeptos de valores antidemocráticos e de pretenderem o monopólio estatal da educação (1999, p. 168).

Além dos artigos publicados em jornais, o autor dedica três obras especificamente à educação, a saber: sua tese de livre-docência, denominada A Ilustração brasileira e a ideia de Universidade (1959), reeditada em 1986, com a apresentação de Antonio Paim, segundo o qual, "tornou-se um marco na história das ideias no Brasil" (PAIM, 1986, p. xi.); Ensaios sobre Educação (1970) e Diretrizes e Bases da Educação Nacional (1960) ${ }^{17}$, organizado durante a Campanha em defesa da Escola Pública ocorrida no final dos anos 1950.

De um aluno estudioso e aplicado, Roque Spencer passa a ser uma referência em História da Educação. Miguel Reale destaca que ao lado da Faculdade de Direito, as pesquisas realizadas por Roque Spencer, na Faculdade de Educação, foram muito importantes para o aprofundamento da história das ideias no Brasil (1994, p. 35). Contudo, destaca que se dedicou mais ao campo da Filosofia da Educação do que à História da Filosofia (1987, p. 220. Vol. II). Luiz Carlos de Menezes diz que sempre considerou Roque Spencer um "intelectual de tendência conservadora", mas não deixava de reconhecer que "ele indiscutivelmente representa uma elite econômico-cultural que teve importante papel na construção da Universidade de São Paulo, elite esta signatária do Manifesto dos Pioneiros de 1932, do qual a USP é decorrente" (MENEZES, 03/03/80). Fernando Henrique Cardoso, que também atuou ao lado de Roque Spencer na CDEP, alguns anos mais tarde afirmava que este autor "celebrizou-se no campo educacional por suas posições liberal-conservadoras" (1988, p. 28). Jorge Nagle, por sua vez, destaca o "incansável rigor e a meticulosidade de Roque Spencer na elaboração de seu trabalho" (1999, p. 97). 
Se é possível destacar um intelectual, dentre tantos que influenciaram decisivamente o trabalho e a trajetória educacional de Roque Spencer, sem sombra de dúvida, esse intelectual é Júlio de Mesquita Filho.

Durante a CDEP, fiel à sua opção liberal, Roque Spencer lutou contra a centralização e as pretensões do Ministério da Educação que queria impor um modelo universitário único para todo o país. Ao lado de Miguel Reale, participou de uma representação de professores junto com Laerte Ramos de Carvalho e Antonio Guimarães Ferri no simpósio promovido pelo Conselho de Reitores em Juiz de Fora. Naquele momento redigiram um documento denominado Manifesto de Juiz de Fora, no qual proclamavam o direito de se auto-organizar segundo critérios próprios. Segundo Reale, neste documento

ficou assente o direito da USP de fixar soluções correspondentes aos índices de seu desenvolvimento científico e tecnológico, como uma Universidade diversificada e plural, capaz, portanto, de corresponder ao multifário panorama das condições geoeconômicas e educacionais paulistanas, sem ser obrigada a ajustar-se ao modelo federal incompatível com a sua grandeza (1994, p. 43).

De certo modo, aí já se encontra o germe do que mais tarde passaria a ser bandeira de luta, a autonomia universitária. Todavia, se nessa época Roque Spencer opunha-se à imposição de um modelo único de educação para todas as universidades, em 1968 fez o contrário. Além de apoiar o governo ditatorial e centralizador de Costa e Silva, aceitou seu convite para participar do Grupo de Trabalho escolhido para elaborar a proposta de Reforma Universitária, quando procurou interferir e defender a extensão do modelo uspiano às demais universidades do país. Da mesma forma, se durante a CDEP defendia a universalização da educação pública, mais tarde critica o governo por permitir o crescimento indiscriminado do ciclo colegial e a "democratização do ensino superior".

Para Roque Spencer, entretanto, as grandes transformações nacionais passavam pela via educacional, não exclusivamente pela educação escolar. Por isso, mais do que escrever e publicar artigos em revistas especializadas na área da educação em que trabalhava, na tentativa de atingir ao maior número de pessoas possível, procurava escrever sistematicamente para os jornais.

Com exceção de dois anos ou, mais especificamente, durante 33 anos, Roque Spencer trabalhou na Universidade de São Paulo, até se aposentar aos 56, em 1984. Todavia, apesar de ter se dedicado longamente à educação, dois anos após sua aposentadoria, afirmava que a educação fora um mero acidente de percurso em sua vida.

Segundo seu colega Moacir Gadotti, Roque Spencer frequentemente afirmava que sua aposentadoria ocorreu um tanto cedo devido ao fato de perceber a decadência qualitativa do ensino, à falta de educação dos estudantes, à mediocridade e aos movimentos grevistas (1986 p. 245).

Ainda que não tenhamos feito uma descrição exaustiva da trajetória educacional de Roque Spencer ${ }^{18}$, por estas linhas é possível perceber algumas aparentes contradições entre a sua teoria e sua prática liberais. Assim, se de um lado o vemos defender teoricamente a "liberdade", de outro, não hesita em apoiar medidas ditatoriais como as do ditador Pinochet. Dissemos aparentemente contraditórias porque, apesar de a ideia de liberdade estar na base do liberalismo, sua premissa essencial e inegociável, não está nela, mas sim na propriedade. 
Deste modo, sempre que esta encontra-se ameaçada, é aquela que é aniquilada e não a propriedade. Ou seja, no tocante ao liberalismo, pode-se dizer que não há nenhuma contradição ou incompatibilidade entre defender o liberalismo e ser adepto às ideias e práticas que, para além do liberalismo, denominamos de conservadoras e autoritárias.

Acometido por Infarto Agudo do Miocárdio, Hipertensão Arterial, Arteriosclerose e Bronquite Crônica, Roque Spencer faleceu às 9:30 horas do dia 08 de maio de 1999, aos 72 anos de idade, em sua residência na capital paulista.

\section{Referências:}

AZANHA, José Mário Pires. Roque Spencer Maciel de Barros: defensor da escola pública. In: Revista da Faculdade de Educação da USP. Educação e Pesquisa. São Paulo: Vol. 25, no 1, jan./Jun. 1999.

BARROS, Benedicto Ferri de. Meu amigo Roque. Centro de Documentação e Informação-CDI-O ESP - O Estado de S. Paulo. Registro de Falecimento. 10/05/1999.

BARROS, Roque S. M. de. A 'Ilustração' brasileira revisitada. In: BARROS, Roque S. M. de. Estudos Brasileiros. Londrina: UEL, 1997.

. A Evolução do Pensamento de Pereira Barreto. São Paulo: Grijalbo, 1967.

Conduta animal e Conduta Humana: amestramento e educação. In: BARROS,

Roque S. M. de. Razão e Racionalidade. São Paulo: T. A. Queiroz, Editor, 1993.

. Obras Filosóficas de Luiz Pereira Barreto. São Paulo: Grijalbo, 1967, Vol. 1.

de. Recordações de Heráclito. In: BARROS, Roque S. M. de. Razão e Racionalidade. São Paulo: T. A. Queiroz, Editor, 1993.

. Os poetas de Orlândia. O Estado de S. Paulo. 03/04/84.

. Introdução à Filosofia Liberal. São Paulo: Grijalbo-Edusp, 1971.

BRITO, Paulo. O professor que conseguiu unir todas as tendências da USP. Jornal da Tarde. 03/03/80.

BUFFA, Ester e NOSELLA, Paolo. A educação negada. São Paulo: Cortez, 1986, p. 50.

CAPELATO, Maria Helena \& PRADO, Maria Lígia. O bravo matutino. Imprensa e ideologia: o jornal O Estado de S. Paulo. São Paulo: Alfa-Omega, 1980.

CARDOSO, Fernando Henrique. Memórias da Maria Antônia. In: SANTOS, Maria Cecília Loschiavos dos. Maria Antônia: uma rua na contramão. São Paulo: Nobel, 1988.

FERNANDES, Florestan. A Contestação Necessária: retratos intelectuais de inconformistas e revolucionários. São Paulo: Ática, 1985.

GADOTTI, Moacir. História das Ideias Pedagógicas. São Paulo: Ática, 1986.

MONARCHA, Carlos (Org.). História da Educação Brasileira: Formação do Campo. Ijuí: Unijuí, 1998. 
MOTA, Carlos Guilherme \& CAPELATO, Maria Helena. História da Folha de São Paulo: 1921-1981.

NAGLE, Jorge. A trajetória da pesquisa em história da Educação no Brasil. In: MONARCHA, Carlos (Org.). História da Educação Brasileira. Ijuí - RS: Unijuí, 1999.

PAIM, Antônio. Apresentação. In: BARROS, Roque S. M. de. A Ilustração Brasileira e a Ideia de Universidade. São Paulo: Convívio: Editora da USP, 1986.

. História das Ideias Filosóficas no Brasil. $3^{a}$ edição, São Paulo: Convívio, 1984.

REALE, Miguel. Memórias. São Paulo: Saraiva, 1987, p. 220. Vol. II.

. Minhas memórias da USP. In: Revista Estudos Avançados. Vol. 8 - nº 22, setembro / dezembro, 1994.

SEVERINO, Antônio Joaquim. A Filosofia Contemporânea no Brasil: conhecimento, política e educação. Petrópolis, Rio de Janeiro: Vozes, 1999.

\section{Notas}

${ }^{1}$ Este artigo tem como referência a Tese de Doutorado defendida em 2003, na Faculdade de Educação da Unicamp, sob a orientação da Prof ${ }^{a}$. Maria Elizabete S. P. Xavier, que trás por título: Liberalismo, neoliberalismo e Educação. Roque Spencer Maciel de Barros, um ideólogo da educação brasileira.

2 Doutor em História e Filosofia da Educação pela Unicamp, docente do Curso de Pedagogia e do Mestrado em Educação da Unioeste, Campus de Cascavel e líder do Grupo de Pesquisa em História, Sociedade e Educação no Brasil - GT da Região Oeste do Paraná - HISTEDOPR.

${ }^{3}$ Jornais da Família Mesquita, à época, representante da elite de São Paulo e da cafeicultura deste Estado. Os Mesquitas, juntamente com Armando de Salles Oliveira (genro de Julio Mesquita), que foi interventor no governo de São Paulo em meados da década de 1930, foram os principais idealizadores da USP.

${ }^{4}$ Por racionalidade Roque Spencer compreende "a atividade, sem dúvida metódica e sistemática, mas submissa ao real e aos fatos, tal como a desenvolveu a Ilustração, como se pode ver (...) nas filosofias de Locke, de Hume, de Voltaire, de D’Alembert, de Diderot ou de Kant. Essa racionalidade, função espiritual e não entidade metafísica, é a obra por excelência da inteligência crítica, sabedora ou no mínimo suspeita de que a atividade da cultura e da ciência não se pode encerrar numa fórmula e que há de estar sujeita, permanentemente, a reparos, revisões e refutações (...)". (BARROS, 1993, p. ix).

${ }^{5}$ Designa por Razão, com inicial maiúscula, "aquela entidade absoluta, que está na base dos grandiosos sistemas do racionalismo clássico e que, depois de ceder o passo à racionalidade (...), durante o século XVIII, voltaria a encarnar-se nas construções monumentais da Filosofia da História, todas elas, no fundo, apriorísticas, como era, confessadamente a de Fichte (...), como acabaram por ser as ideologias características do século XIX, de Comte ou de Marx, este o herdeiro do apriorismo hegeliano, a deduzir dialeticamente a História, como um dos grandes momentos da realização do Espírito, se desdobrando na Lógica, primeiro, e, a seguir, na Filosofia da Natureza que precederia o evoluir histórico". (Idem. p. ix)

6 A expressão “cientificismo” não foi criada por Roque Spencer, mas ele ajudou a fixá-la. Quando analisarmos o liberalismo e o cientificismo veremos que, para o autor, o cientificismo estabelece sua base na confiança e no valor do conhecimento científico tido como capaz de desvendar o conhecimento da história e do ser, tornando possível, a partir do que é, definir o que deve ser e o que é efetivamente valioso. Para ele, está ligado à ideia totalitária. Por isso, diz que prefere adotar apenas a expressão cientismo ou cientista. "Recuso-me a usá-la (a não ser que o faça por descuido), empregando a expressão que deveria ter usado sempre: cientismo e 'cientista' (entre aspas, para evitar confusão), em lugar de cientificismo e cientificista, que soam mal aos meus ouvidos. Embora a expressão 'cientista', mesmo entre aspas, possa, como já disse, gerar alguma confusão, pois se refere 
ao adepto do cientismo e não ao cientista propriamente dito, prefiro a confusão à palavra inexistente e mal formada". (Cf. BARROS, 1997, pp. 63-64 e MONARCHA, 1998, pp. 24-25). Apesar disso, Roque Spencer frequentemente, utiliza a expressão de forma indistinta. Por isso, mesmo sabendo da preocupação do autor, ao longo do trabalho, para uniformizar, continuaremos utilizando a expressão cientificismo.

${ }^{7}$ Mais tarde Roque Spencer situa Barreto como "representante típico da mentalidade cientificista".

${ }^{8}$ Num bilhete encaminhado a Antônio Joaquim Severino manifestando sua discordância devido ao fato de ter sido classificado como culturalista, Roque Spencer autodefiniu-se simplesmente como um liberal (Cf. SEVERINO, 1999, p. 149).

${ }^{9}$ Bilhete encaminhado ao professor Antônio Joaquim Severino em 1999.

${ }^{10}$ Sobre Laerte Ramos de Carvalho, que faleceu em 1972, às vésperas de seu quinquagésimo aniversário, nos ocuparemos principalmente nos segundo e quinto capítulos da terceira parte deste trabalho.

${ }^{11}$ Expressão que utiliza emprestada de Max Scheler.

${ }^{12}$ Ao prestar concurso para obtenção do título de Doutor em História e Filosofia da Educação na antiga FFCL/USP integraram a banca do concurso os seguintes docentes: Laerte Ramos de Carvalho, Lívio Teixeira, José Quirino Ribeiro, Eurípedes Simões de Paula e Antônio Cândido de Mello e Souza.

${ }^{13}$ Ao prestar concurso para obtenção do título de Livre-docente da cadeira de História e Filosofia da Educação na antiga FFCL/USP integraram a banca do concurso os seguintes docentes: Raul Bittencourt, Abgar Renault, Mario Wagner Vieira da Cunha, João Cruz Costa e Laerte Ramos de Carvalho.

${ }^{14}$ Não conseguimos saber o nome dos componentes da banca deste concurso.

${ }^{15}$ Ao prestar concurso para Professor Titular participaram da banca os seguintes professores: Sérgio Buarque de Holanda, José Quirino Ribeiro, Aderaldo Castelo, Ivan Lins e Alvaro Magalhães.

${ }^{16}$ Cf. GADOTTI, 1986, p. 245). Florestan Fernandes relata o seguinte fato: "trabalhando juntos (com Fernando de Azevedo), ele nos delegou e nós dávamos cursos. Houve a revolução das notas, que vale a pena contar. É necessário ver como as coisas se passavam na cabeça dos professores brasileiros, que tinham a capacidade de lecionar numa universidade. Eu corrigia as provas, eu ficava com uma parte e o Antonio Cândido com outra. Certa vez corrigindo provas, dei dez ao hoje professor Roque Spencer Maciel de Barros. O Dr. Fernando opunha-se a que se desse dez. Quando ele viu a nota, fez um ar contrariado: 'Você pôs dez. Mas dez por quê? 'Porque foi um trabalho muito bem-feito para um estudante'. Ele disse: 'Bem, eu venho de uma tradição, de uma escola na qual dez era para Deus, nove para os professores e, para alunos excepcionais a partir de oito'. Eu disse; Bem, doutor, então o senhor passe a ler as provas, porque os nossos critérios de nota colidem" (FERNANDES, 1985. p. 190).

${ }^{17}$ Esta é uma obra importantíssima, de consulta indispensável aos historiadores da educação brasileira, para conhecer a confluência de pessoas e as lutas que foram travadas em Defesa da Escola Pública nos anos 50, bem como para conhecer como foi o percurso do Projeto de Lei de Diretrizes e Bases da Educação Nacional, desde 1948 até 1959.

${ }^{18}$ Aos interessados em aprofundar os conhecimentos acerca de Roque Spencer, sua trajetória intelectual e sua obra, indicamos nossa Tese de doutorado intitulada "Liberalismo, neoliberalismo e educação. Roque Spencer Maciel de Barros, um ideólogo da Burguesia Brasileira", defendida em 2003, na Unicamp.

Recebido em novembro-13

Aprovado em novembro-13 